Preprint of Mevel, R., F. Rostand, D. Lamrie, L. Breyton, and J.E. Shepherd. 2018. "Oxidation of n-Hexane in the Vicinity of the Auto-Ignition Temperature." Fuel 236, 373-381, 2019. https://doi.org/10.1016/j.fuel.2018.09.009

\title{
Oxidation of $n$-Hexane in the Vicinity of the Auto-Ignition Temperature
}

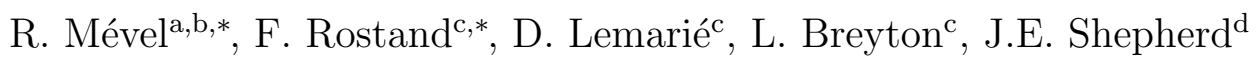 \\ ${ }^{a}$ Center for Combustion Energy, Tsinghua University, \\ Beijing 100084, China \\ ${ }^{b}$ Department of Automotive Engineering, Tsinghua University, \\ Beijing 100084, China \\ ${ }^{c}$ École Polytechnique Paris, 91128 Palaiseau Cedex, France \\ ${ }^{d}$ Graduate Aerospace Laboratories, California Institute of Technology, \\ 1200 E. California Blvd, Pasadena, California 91125, USA
}

\begin{abstract}
The present study examines the possibility of inerting flammable mixtures (making the mixtures non-explosive/non-flammable) using a long duration thermal process close to but below the auto-ignition temperature. Experiments were performed in a stainless steel cell and a Pyrex cell. A Mid-IR FTIR spectrometer, a UV-Vis spectrometer and several IR laser diodes were employed to monitor the gas-phase composition. Experiments were performed for $n$-hexane-air mixtures with $\Phi=0.67-1.35$. The temperature and pressure were $\mathrm{T}=420-500 \mathrm{~K}$ and $\mathrm{P}=37-147 \mathrm{kPa}$. Experiments were performed over period of up to $7200 \mathrm{~s}$. At temperatures close to $420 \mathrm{~K}$, the chemical activity is characterized by a slow and constant reaction rate. At temperatures close to $500 \mathrm{~K}$, the reaction proceeds in two-phases: 1) rapid production of $\mathrm{CO}_{2}, \mathrm{CO}$ and carbonyls, identified as hydroperoxy-ketones, followed by 2) a period of slower production of $\mathrm{CO}_{2}$ and $\mathrm{H}_{2} \mathrm{O}$ and consumption of hydroperoxy-ketones. At the end of the thermal treatment, the possibility of igniting the mixtures using a large hot surface (representative of low-temperature ignition source) and a stationary concentrated hot surface (representative of high-temperature ignition source) was tested. The low-temperature flammability was verified by rapidly increasing the temperature of the test cell wall whereas the high-temperature flammability was verified by turning on a glow plug. The inerting strategy seems effective in
\end{abstract}

\footnotetext{
${ }^{*}$ Corresponding author: mevel@mail.tsinghua.edu.cn
} 
preventing the low-temperature ignition but high-temperature ignition was always observed.

Keywords: Ignition, Safety, Spectroscopy, Low-temperature oxidation 


\section{Introduction}

Accidental combustion events in fuel tanks and flammable leakage zone is a major concern in aviation safety [1, 2, 3, 4]. For example, the National Transport Safety Board investigation pointed out that the explosion of the center wing fuel tank resulting from the ignition of the flammable atmosphere in the tank as the probable cause of the flight TWA 800 accident in 1996 [5]. Possible ignition sources include electrical sparks $[1,6,7,8,9]$, stationary hot surfaces $[2,3,4]$ and moving hot particles $[10,11,12]$. In 2008, the Federal Aviation Administration published the Fuel Tank Flammability Reduction Rule [13] requiring the installation of a flammability reduction or ignition reductions means for the fuel tanks that are most at risk. A number of inerting strategies can potentially be employed to reduce or eliminate the risk of accidental explosion in the fuel tanks of aircraft $[14,15,16]$. In the framework of aircraft safety, the term "inert mixture/environment" designates a non-flammable or non-explosive mixture, not necessarily a mixture in which no reaction is taking place. One commonly-used strategy in military aircraft is explosion suppression with a polyurethane reticulated foam, within the fuel tank. The applicability of this effective approach to commercial aircraft is limited due to the reduction of the volume available for fuel, an increased weight of the fuel tank, maintenance complication, and limited life-time. There are a number of other possible strategies, such as inerting with liquid nitrogen and inerting with halon, that have been examined $[14,15,16]$ but the most practical one that is in use today is on-board inert gas generation system (OBIGGS). The OBIGGS is based on a hollow fiber membrane that exhibits selective permeability so that a nitrogen-enriched environment is created in the fuel tank [15]. The nitrogen-enriched stream may be employed to "wash" the fuel ullage to eliminate the gas-phase oxygen and/or to "scrub" the liquid fuel to eliminate the dissolved oxygen. Extensive studies have been carried out $[15,17]$ to assess the effect of various parameters of the OBIGGS technique including the flow rate of the inert gas, the concentration of oxygen in the nitrogen-enriched stream, and the fuel mass loading of the tank.

Although effective, the OBIGGS strategy has limitations, such as the weight and the complexity of the system transporting bleed air. A potential alternative approach 
to OBIGGS is low-temperature oxidation: through a long duration thermal process close to but below the auto-ignition temperature, the flammable fuel-air mixture could be converted into an inert mixture. This mixture can then be re-injected in the fuel tank in order to reduce the oxygen concentration below the flammability limit. Recent results obtained at the Explosion Dynamics Laboratory [2, 3] have demonstrated that under certain conditions of pressure, composition and heating rate, $n$-hexane-air mixtures can undergo a slow oxidation process in the vicinity of the auto-ignition temperature without explosion. Since the large majority of the studies on hydrocarbon fuel oxidation are performed for short residence times and over a range of temperature in which ignition is taking place $[18,19]$, the chemical dynamics of hydrocarbons in the vicinity of the auto-ignition temperature and over long residence time is much less known.

The present study examines a long duration thermal process close to but below the auto-ignition temperature to create an inert mixture through slow oxidation for a range of $n$-hexane-air mixtures. The evolution of the gas-phase composition is monitored over tens of minutes using ultraviolet and infra-red spectroscopy and the flammability of the resulting mixture is verified using both low- and hightemperature ignition sources.

\section{Materials and methods}

\subsection{Mixture preparation}

For all the experiments, the mixtures were prepared in a separate evacuated stainless-steel mixing vessel using the partial pressure method. Liquid $n$-hexane with $99 \%$ purity was first injected in the mixing vessel to the appropriate pressure which depends on the equivalence ratio. The oxygen to $n$-hexane ratio was selected to give the desired equivalence ratio: the stoichiometric value is 9.5:1. Synthetic air (nitrogen to oxygen ratio 3.76) was added to the fuel and the mixture was actively mixed for an hour using an electrical fan inside the mixture vessel. The mixture was then transferred into a glass flask which was connected to the test cell. Introduction of the gas mixture into the test cell was performed after the cell was evacuated and 
had reached the desired temperature. The residual pressure following evacuation was less than $10 \mathrm{~Pa}$. Based on the accuracy of the pressure sensors used to prepare the mixtures, the uncertainty of the component mole fractions was less than $2 \%$.

\subsection{Test cells}

The experiments were performed using two test cells. The first cell was employed to study the evolution of the gas-phase composition and the high-temperature flammability (using the glow plug). The second cell was employed to test the lowtemperature flammability (using the heated Pyrex vessel).

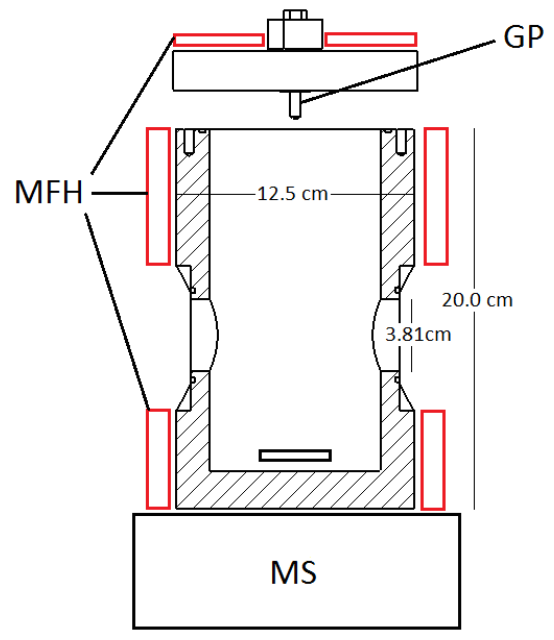

(a) Vessel and heating system, section view

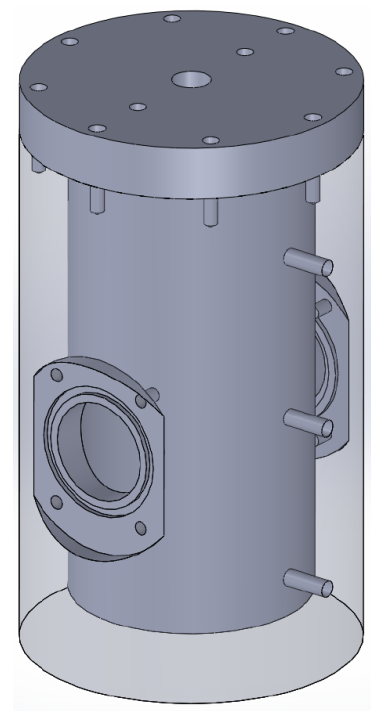

(b) SolidWorks 3D view

Figure 1: Schematic and 3D view of the test cell. GP: Glow Plug, MS: Magnetic Stirrer, MFH: Mica Foil-Heaters (in red).

The first cell is a 1.14 L cylindrical cell made of stainless steel shown in Figure 1. Two $5 \mathrm{~cm}$ in diameter, $5 \mathrm{~mm}$ thick ZnSe windows are located opposite to each other for optical access. The test vessel is equipped with pneumatic valves for rapid filling, gas sampling and evacuation. The temperature and pressure inside the cell are monitored using a shielded K-type thermocouple (uncertainty of 1\%) and a pressure transducer (uncertainty of $3 \%$ ) both from Omega. Mica foil or ceramic heaters and a heated magnetic stirrer plate are used along with temperature controllers to heat the vessel and maintain the temperature constant. 
The second cell is the one used in Boettcher et al. [2]. Briefly, it is a closed $400 \mathrm{~mL}$ Pyrex cell equipped with two sapphire windows spaced $9 \mathrm{~cm}$ apart for optical access. The vessel was placed inside an aluminum shell which was heated by two band heaters with a maximum power of $800 \mathrm{~W}$. The temperature inside the vessel was measured using a shielded K-type thermocouple while the pressure was monitored using a pressure transducer.

Signals from the thermocouple and the pressure transducer were recorded using acquisition cards and an in-house Labview program.

It is noted that, given the large size of the experimental matrix we investigated, only one experiment has been performed at each set of conditions.

\subsection{Spectroscopic diagnostics}

In a series of experiments, the composition of the gas-phase was monitored using a Frontier Perkin-Elmer Mid-IR FTIR (Fourier Transform InfraRed) spectrometer. Spectra were collected over a wide spectral range: from 1000 to $4000 \mathrm{~cm}^{-1}$. The resolution used was $1 \mathrm{~cm}^{-1}$ at a sampling rate of $0.2 \mathrm{~Hz}$. These experiments enabled monitoring absorption $\mathrm{CO}, \mathrm{CO}_{2}, \mathrm{H}_{2} \mathrm{O}$, and by the $\mathrm{C}-\mathrm{H}, \mathrm{C}-\mathrm{O}$, and $\mathrm{C}=\mathrm{O}$ bonds .

The FTIR results were complemented by experiments performed with a number of absorption based measurements to characterize the dynamics of carbonyls, hexane, oxygen and water vapor. For these additional experiments, the combustion cells were placed in a large airtight PVC box continuously flushed with dry nitrogen and in which desiccant was introduced in order to mitigate the contributions of background oxygen and water vapor.

Identification of the carbonyls formed during the thermal treatment was attempted using UV absorption. An Ocean Optics USB-4000 UV-Vis spectrometer was used. It has a resolution of $1 \mathrm{~nm}$ and an optical bandwidth from 200 to 900 nm. A $0.1 \mathrm{~Hz}$ sampling rate was used. The UV-Vis absorption experiments were conducted using an ENERGETIQ EQ-99XFC laser driven light source. It delivers $80 \mathrm{~mW}$ of white light over the spectral range 190-2100 nm. 
A He-Ne laser emitting at $3.39 \mu \mathrm{m}$ was employed to monitor the evolution of the fuel concentration in terms of $\mathrm{C}-\mathrm{H}$ bond equivalent [20]. To avoid saturation of the detector (Thorlabs PDA20H), the incident light beam was mechanically chopped at $100 \mathrm{~Hz}$.

Oxygen was detected near $763.5 \mathrm{~nm}$ using scanned wavelength modulation spectroscopy (WMS) with a 1f-normalized $2 \mathrm{f}$ detection [21, 22]. A saw-tooth signal with frequency of $2 \mathrm{~Hz}$ and amplitude of $120 \mathrm{mV}$ was employed to scan across the absorption line while a sine waveform with frequency of $1 \mathrm{kHz}$ and $4 \mathrm{mV}$ amplitude was used for modulation. A dual-pass scheme was employed for this diagnostic. Detection was made with a Thorlabs PDA10A.

Detection of water vapor was also performed using scanned WMS with a 1f-normalized $2 \mathrm{f}$ detection. The absorption features near $1392.5 \mathrm{~nm}$ were scanned across at a $2 \mathrm{~Hz}$ frequency with a saw-tooth signal of $2.5 \mathrm{~V}$ of amplitude. The modulation was performed with a sine waveform with amplitude of $22 \mathrm{mV}$ and frequency of $1 \mathrm{kHz}$. An off-axis multi-pass Herriot scheme was implemented for this diagnostic. A Thorlabs PDA50B detector was employed for monitoring the signal.

For both WMS diagnostics, two SR830 lock-in amplifiers were employed to enable the simultaneous monitoring of both $1 \mathrm{f}$ and $2 \mathrm{f}$ signals. Acquisition was performed using National Instruments acquisition cards and an in-house Labview program.

All the species profiles were normalized using the maximum value of the raw signal observed during the course of one experiment. It is noted that we did not intend to obtain quantitative information for the species concentrations (except for $\mathrm{CO}_{2}$ partial pressure) and the value of these data is in the qualitative trends. As a consequence, it is not really meaningful to define uncertainties. For quantifying the $\mathrm{CO}_{2}$ partial pressure, we have performed a separate calibration with an uncertainty on the order of 5\%. For the other absorption diagnostics, quantitative assessment of the species concentrations was complicated by (i) the need for performing calibrations, (ii) the unknown absorption cross-section (mostly for hydroperoxy-ketones), and (iii) the need for using a complex simulation procedure (for WMS [22]) which requires significant development. 


\subsection{Flammability tests}

To test the flammability at low temperature, the Pyrex test cell was employed. Following the thermal treatment, the temperature of the aluminum shell was increased at a rate up to $8 \mathrm{~K} / \mathrm{min}$. Possible ignition was detected using the pressure transducer and laser absorption at the He-Ne laser wavelength. The Pyrex cell was used because it had a much lower thermal inertia than the stainless steel cell; this enabled a much higher heating rate than possible in the metal vessel.

To test the flammability at high temperature, the stainless steel cell was equipped with a diesel engine glow plug, see Figure 1. This glow plug installation is similar to that used by Boettcher $[3,4]$ except the glow plug is oriented downward in the present study. The glow plug used was a commercially available Autolite 1110, which can reach a temperature above $1300 \mathrm{~K}$. Following the thermal treatment to slowly oxidize the fuel, flammability was determined by functioning the glow plug and checking for the occurrence of ignition by monitoring the signals from the pressure transducer and a photomultiplier tube equipped with a pass-band optical filter centered at 307 $\mathrm{nm}$ to select the $\left(\mathrm{A}^{2} \Sigma^{+}-\mathrm{X}^{2} \Pi\right)$ transition of the excited $\mathrm{OH}^{*}$ radicals.

\section{Results and discussion}

\subsection{Thermal stability of n-hexane-oxygen-nitrogen mixtures}

\subsubsection{Identification of the species}

Figure 2 shows the temporal evolution of the IR spectrum of a lean hexane-air mixture at $\mathrm{T}=423 \mathrm{~K}$ and at $\mathrm{T}=497 \mathrm{~K}$. In both cases, no spontaneous ignition was observed but detectable amounts of $\mathrm{CO}_{2}$ and $\mathrm{H}_{2} \mathrm{O}$ were formed. At $\mathrm{T}=497 \mathrm{~K}$, a larger variety of chemical species, such as $\mathrm{CO}$ and compounds with $\mathrm{C}=\mathrm{O}$ and $\mathrm{C}-\mathrm{O}$ bonds, are observed. The spectra obtained at different times for the $\mathrm{T}=497 \mathrm{~K}$ case, Figure $2 \mathrm{~b}$ ), show that the absorption bands formed in the range 1000-2000 $\mathrm{cm}^{-1}$ (the range which characterizes $\mathrm{C}-\mathrm{H}$ bond bending) appear at an early stage of the oxidation process and remain essentially constant after several hundred seconds. 


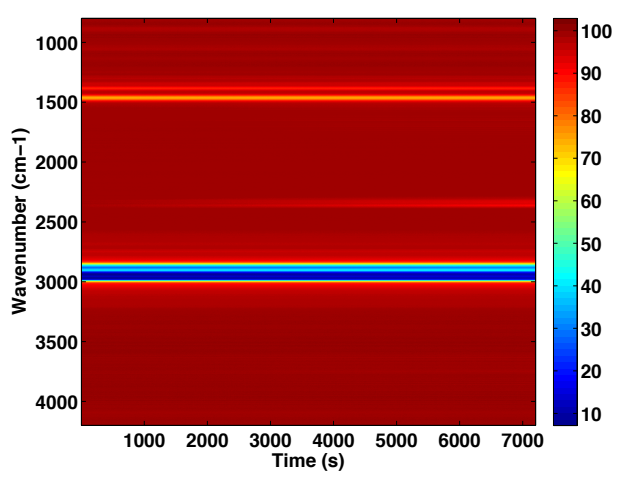

a) Time-resolved spectrum at $\mathrm{T}=423 \mathrm{~K}$ and $\mathrm{P}=142 \mathrm{kPa}$

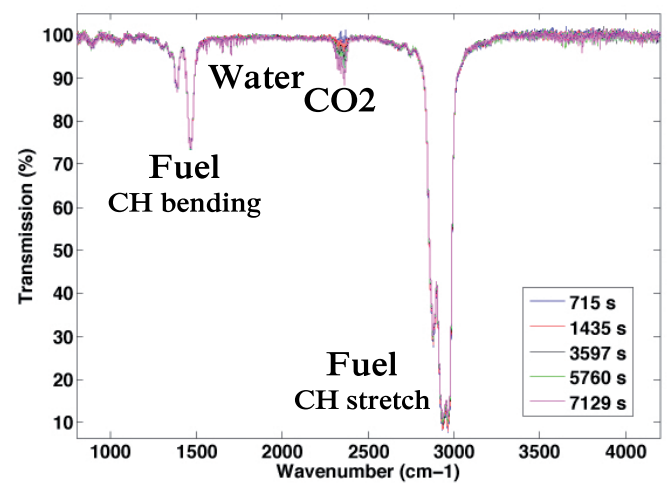

c) IR spectra

at $\mathrm{T}=423 \mathrm{~K}$ and $\mathrm{P}=142 \mathrm{kPa}$

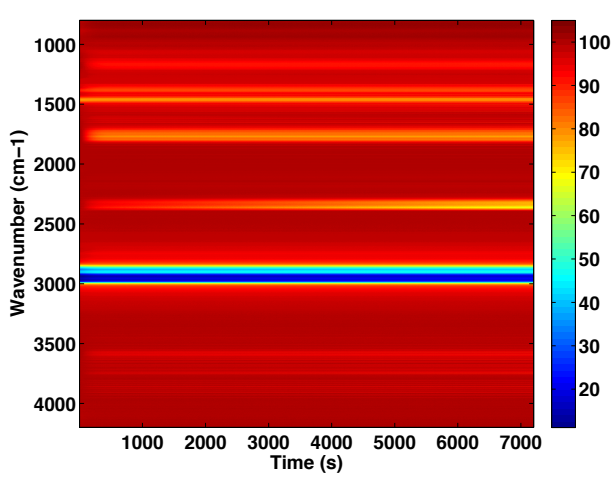

b) Time-resolved spectrum at $\mathrm{T}=497 \mathrm{~K}$ and $\mathrm{P}=147 \mathrm{kPa}$

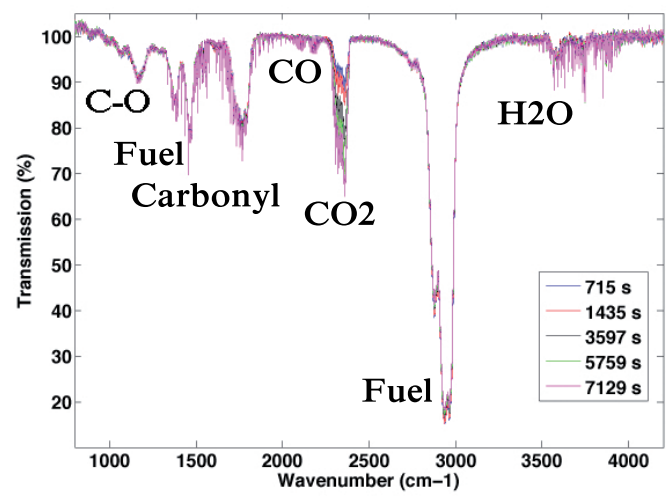

d) IR spectra

at $\mathrm{T}=497 \mathrm{~K}$ and $\mathrm{P}=147 \mathrm{kPa}$

Figure 2: Evolution of the IR spectra of a lean $n$-hexane-air mixture at two temperatures. Conditions: a) and c): $\Phi=0.64, \mathrm{~T}=423 \mathrm{~K}, \mathrm{P}=142 \mathrm{kPa}$; b) and d): $\Phi=0.64, \mathrm{~T}=497 \mathrm{~K}, \mathrm{P}=147 \mathrm{kPa}$. The quantity displayed corresponds to percentage of transmission. 


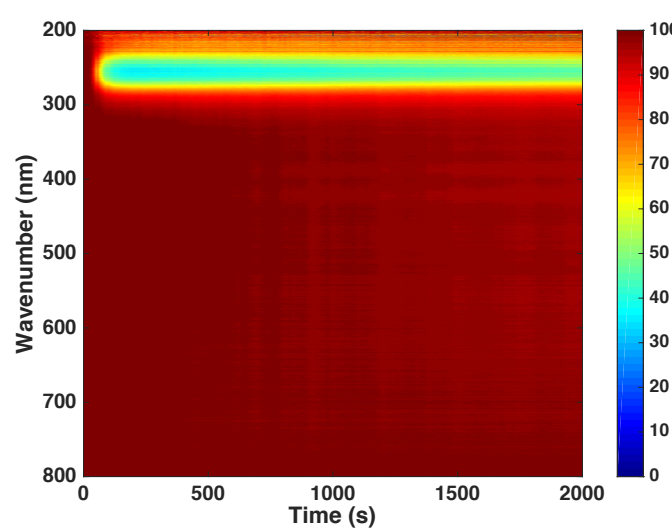

a) Time-resolved spectrum

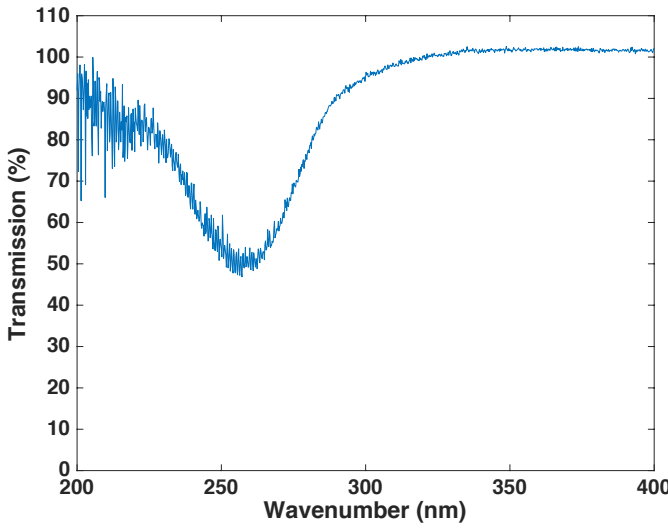

b) Wavelength-resolved spectrum

Figure 3: Time-resolved and wavelength-resolved UV spectra of a stochiometric $n$-hexane-air mixture. Conditions: $\Phi=1, \mathrm{~T}=500 \mathrm{~K}, \mathrm{P}=101 \mathrm{kPa}$. The quantity displayed corresponds to percentage of transmission.

In order to gain deepler insight into the formation of carbonyl compounds during the oxidation process, UV absorption diagnostics were performed. Figure 3 a) shows the temporal evolution of the UV-visible spectrum for a stoichiometric hexane-air mixture at $500 \mathrm{~K}$ and $100 \mathrm{kPa}$. Note that no significant absorption feature was detected at 420 and $470 \mathrm{~K}$. After 50 to $100 \mathrm{~s}$, a broad-band absorption feature is observed between 220 and $290 \mathrm{~nm}$. Figure $3 \mathrm{~b}$ ) shows the wavelength-resolved UV-vis spectrum obtained $100 \mathrm{~s}$ after the introduction of the gas in the heated vessel. The absorption peak is located at a wavelength close to $260 \mathrm{~nm}$. This absorption feature remains intense until the end of the experiment, $2000 \mathrm{~s}$. The absorption cross-section in the UV of a variety of carbonyls are available from the UV/VIS Spectral Atlas of the Max Planck Institute of Mainz [23]. Aldehydes typically demonstrate a peak of absorption around $290 \mathrm{~nm}$ (see Limao-Vieira et al. [24] and Martinez et al. [25] for acetaldehyde, Chen et al. [26] and Martinez et al. [25] for n-butanal, and Tang and Zhu [27] and Jimenez et al. [28] for n-hexanal) except formaldehyde which absorption peak is above $300 \mathrm{~nm}[29,30]$. In addition, we note that the UV absorption spectra of ketones typically show a maximum around $280 \mathrm{~nm}$ (see Horowitz from [23] for 3-hexanone and Yujing and Mellouki [31] for 2-butanone). Consequently, the UV spectra registered during the present experiments seem consistent only with the 
hydroperoxy-ketones spectra obtained by Jorand et al. [32] with a maximum at 260-265 nm.

\subsubsection{Time-resolved profiles}

Figure 4 illustrates the evolution of the normalized concentrations of the main compounds determined from the FTIR measurements during the low-temperature oxidation of some $n$-hexane-air mixtures for three selected temperatures. From Figure $4 \mathrm{a}$ ), it is observed that the absorptions at the bands of $\mathrm{C}=\mathrm{O}$ and $\mathrm{C}-\mathrm{O}$ bonds reach 80 to $90 \%$ of their final values within about $430 \mathrm{~s}$ for a temperature of $497 \mathrm{~K}$. At a lower temperature of $466 \mathrm{~K}$, it takes $1500 \mathrm{~s}$ for the absorption at these bands to reach similar values. The concentrations of $\mathrm{CO}, \mathrm{H}_{2} \mathrm{O}$ and $\mathrm{CO}_{2}$ increase only to $30-50 \%$ of their final values within few hundred of seconds (500 s at $497 \mathrm{~K}$ and 2000 $\mathrm{s}$ at $466 \mathrm{~K})$ and then increase at a lower rate. On the FTIR spectra, the absorption due to $\mathrm{C}-\mathrm{H}$ bonds, between $2840-3000 \mathrm{~cm}^{-1}$, does not seem much affected by the oxidation process. However, measurements performed using the He-Ne laser at $2950 \mathrm{~cm}^{-1}(3.39 \mu \mathrm{m})$ demonstrate that a significant, up to $25-50 \%$ depending on the temperature, change of hexane-equivalent $\mathrm{C}-\mathrm{H}$ bonds is taking place. This is consistent with the calculations of Boettcher et al. [2]. The difference between the FTIR and the He-Ne laser measurements may be due to the too low resolution of the FTIR spectrometer and the high sensitivity of the absorption cross-section at 3.39 $\mu \mathrm{m}$ to the molecular structure $[20,33,34,35,36,37,38]$. This was observed in the FTIR study of fatty acid methyl esters by Campbell et al. [39]. At the He-Ne laser frequency, the local absorption intensity due to $\mathrm{C}-\mathrm{H}$ stretch can vary substantially depending on the chemical species because of the displacement of the absorption features with respect to the narrow line of the laser.

Figure 5 shows the normalized concentration profiles for the fuel, oxygen, water vapor and hydroperoxy-ketones obtained by direct absorption and wavelength modulation spectroscopy. For the two reactants, a fast decrease of the concentration is observed starting from the introduction of the mixture until approximately 400-500

s. Following this fast decrease, no significant consumption is observed. During the 


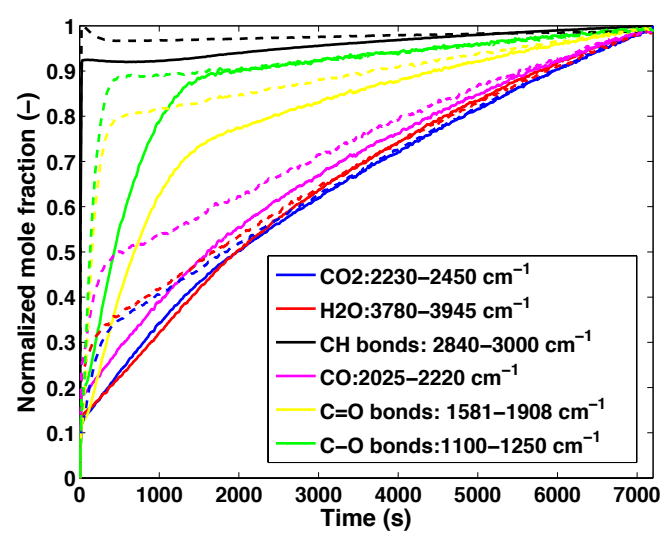

a) Normalized profiles from FTIR

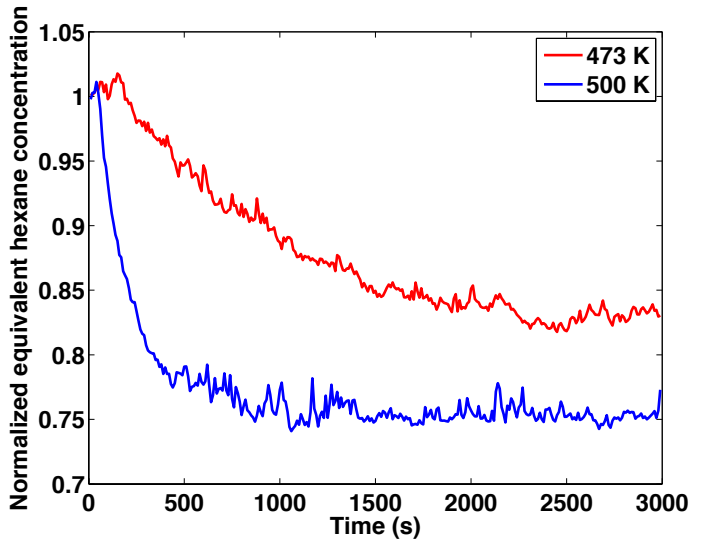

b) Normalized $\mathrm{CH}$ bond profiles from He-Ne laser

Figure 4: Evolution of normalized species profiles during the low-temperature oxidation of $n$ hexane-air mixtures. Conditions: a): $\Phi=0.65, \mathrm{~T}=466 \mathrm{~K}$ (solid) and $\mathrm{T}=497 \mathrm{~K}$ (dashed), $\mathrm{P}=143$ $\mathrm{kPa} ; \mathrm{b}): \Phi=1.1, \mathrm{~T}=473$ and $500 \mathrm{~K}, \mathrm{P}=106 \mathrm{kPa}$.

first part (up to $200 \mathrm{~s}$ ) of the period of fast reactant consumption, a rapid production of hydroperoxy-ketones is observed. Then, the hydroperoxy-ketones are slowly and continuously consumed. The rapid production of water vapor is slightly off-set as compared to that of the hydroperoxyketones with the peak concentration observed around $500 \mathrm{~s}$. Following this time, a slow decrease of the water concentration is observed. This behavior is different from that observed with the FTIR which showed continuous production of water vapor. This might be explained by the variation of the water content inside the PVC box which complicates the precise measurement of the water content within the oxidation vessel. In addition, it should be noted that the multi-pass WMS diagnostics is sensitive to slight variation of the path-length due to temperature variation during the oxidation process. Such an effect was particularly important in our previous study, see Boettcher et al. [2], during which the thermal expansion of the reactor prevented any physically meaningful measurement with the WMS technique.

From Figure 2 to Figure 5, we conclude that for temperature close to the autoignition temperature $(\approx 500 \mathrm{~K})$, the oxidation process appears to be characterized by 


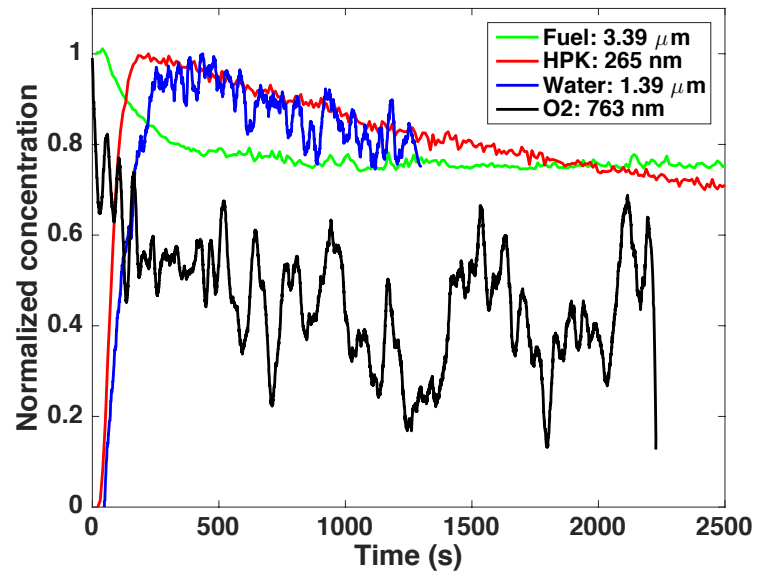

Figure 5: Evolution of normalized concentration of fuel, oxygen, water vapor and hydroperoxyketones (HPK) during the low-temperature oxidation of a rich $n$-hexane-air mixture. Conditions: $\Phi=1.1, \mathrm{~T}=495 \mathrm{~K}, \mathrm{P}=120 \mathrm{kPa}$.

a two-phase reaction: 1) rapid production of $\mathrm{CO}_{2}, \mathrm{CO}$, water, hydroperoxy-ketones and rapid consumption of $\mathrm{C}-\mathrm{H}$ bonds as well as $\mathrm{O}_{2}$; followed by 2) a period of slower production of $\mathrm{CO}_{2}$ and $\mathrm{H}_{2} \mathrm{O}$ and consumption of hydroperoxy-ketones.

\subsubsection{Rate of the oxidation process}

Because the absorption of $\mathrm{CO}_{2}$ in the range $2230-2450 \mathrm{~cm}^{-1}$ is intense and isolated from that of other species, and observed under all the conditions studied, the production of $\mathrm{CO}_{2}$ was most thoroughly examined. Figure 6 a) and b) show the temporal evolution of the carbon dioxide partial pressure for different temperatures and pressures. The results shown in Figure 6 a) illustrate that, depending on the conditions, the oxidation proceeds according to either a single-phase or a two-phase reaction. For temperatures less than 450-470 K, the chemical activity is characterized by a low and constant reaction rate. At higher temperatures, in the range 470-500 K, the reaction proceeds in two phases with an initial fast production of $\mathrm{CO}_{2}$ for several hundred seconds followed by a period of much slower production. From Figure $6 \mathrm{~b}$ ), it is seen that at $40 \mathrm{kPa}$ and $\mathrm{T}=470 \mathrm{~K}$, the production of $\mathrm{CO}_{2}$ is slow and constant, whereas for higher pressures (100 and $140 \mathrm{kPa}$ ) and a similar temperature of $470 \mathrm{~K}$, a two-phase oxidation process is observed. When a two-phase oxidation process was observed, the rate of reaction during the first phase seemed 
not to depend on pressure since the same slope for the $\mathrm{P}_{\mathrm{CO} 2}=\mathrm{f}(\mathrm{t})$ line is observed for 100 and $140 \mathrm{kPa}$. However, the first phase extended over $500 \mathrm{~s}$ at $\mathrm{P}=100 \mathrm{kPa}$ and over $1500 \mathrm{~s}$ at $\mathrm{P}=140 \mathrm{kPa}$.

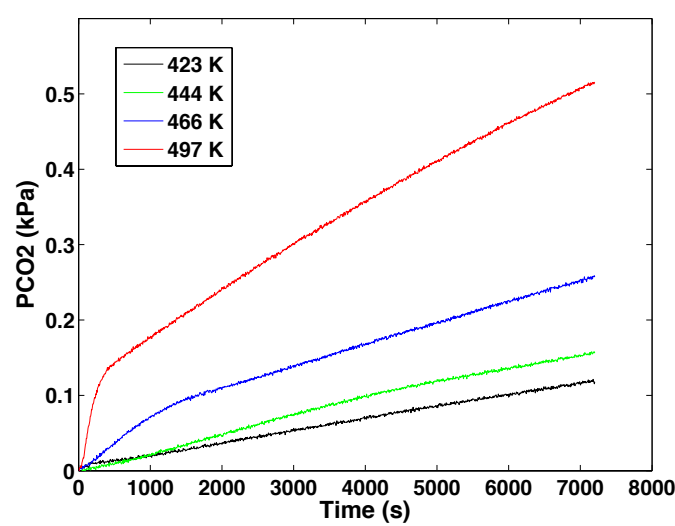

a) Effect of temperature

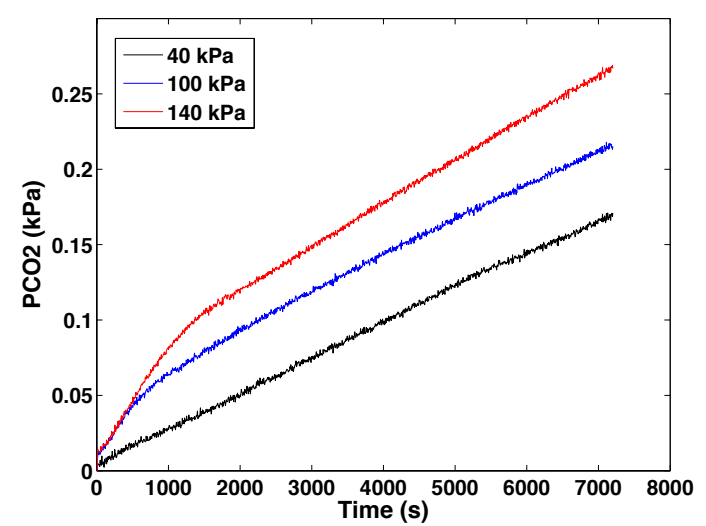

b) Effect of pressure

Figure 6: Carbon dioxide partial pressure profile during the low-temperature oxidation of a lean $n$ hexane-air mixture for different temperatures and pressures. Conditions: a): $\Phi=0.65, \mathrm{~T}=420-500$ $\mathrm{K}, \mathrm{P}=140 \mathrm{kPa} ; \mathrm{b}): \Phi=0.65, \mathrm{~T}=470 \mathrm{~K}, \mathrm{P}=40-140 \mathrm{kPa}$.

The reaction rate of the oxidation process was characterized using the rate of production of carbon dioxide. Figure 7 a) illustrates the approach employed to derive the production rate of $\mathrm{CO}_{2}$. Figure $7 \mathrm{~b}$ ) shows the evolution of the reaction rate as a function of the inverse temperature. Dashed lines account for the first (fast) phase of the process, while solid lines account for the second phase. The first phase has a rate up to an order of magnitude higher. The activation energy of the first step of oxidation is approximately $100 \mathrm{~kJ} / \mathrm{mol}$ whereas that of the second stage increases from $10 \mathrm{~kJ} / \mathrm{mol}$ at $\mathrm{P}=40$ and $70 \mathrm{kPa}$ to $25 \mathrm{~kJ} / \mathrm{mol}$ at $\mathrm{P}=100$ and $140 \mathrm{kPa}$.

\subsubsection{Discussion on the species dynamics}

In the temperature range $500-600 \mathrm{~K}$ and at pressure on the order of $100 \mathrm{kPa}$, ignition of large alkanes such as $n$-hexane or $n$-heptane is a direct consequence of the so-called "low-temperature chemistry" [40, 41, 42]. The main steps leading to ignition are [42]: 


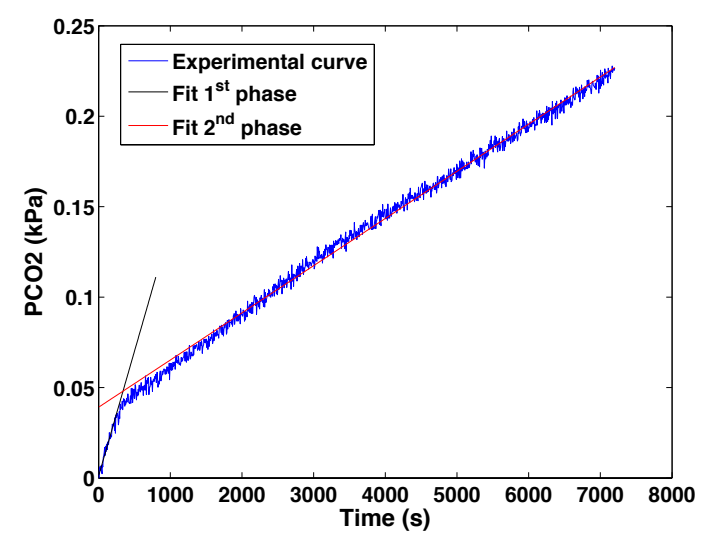

a) Fitting procedure

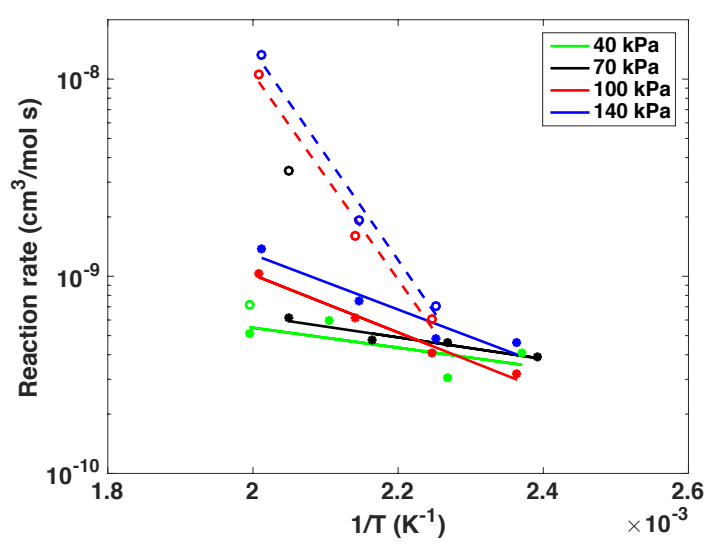

b) Arrhenius plot

Figure 7: Characterization of the rate of $\mathrm{CO}_{2}$ production during the low-temperature oxidation of a lean $n$-hexane-air mixture. Conditions: a): $\Phi=0.65, \mathrm{~T}=488 \mathrm{~K}, \mathrm{P}=76 \mathrm{kPa} ; \mathrm{b}): \Phi=0.65, \mathrm{~T}=418-501$ $\mathrm{K}, \mathrm{P}=38-147 \mathrm{kPa}$. Solid lines and full symbols: second oxidation phase. Dashed lines and open symbols: first oxidation phase.

- $R_{1}: R H \stackrel{\mathrm{O}_{2}, \mathrm{OH}}{\longrightarrow} R$.

- $R_{2}: R \cdot \stackrel{\mathrm{O}_{2}}{\longleftrightarrow} \mathrm{ROO}$.

- $R_{3}: \mathrm{ROO} \longleftrightarrow \cdot \mathrm{QOOH}$

- $R_{4}: \cdot \mathrm{QOOH} \stackrel{\mathrm{O}_{2}}{\longleftrightarrow} \cdot \mathrm{OOQOOH}$

- $R_{5}: \cdot O O Q O O H \longrightarrow H O O \dot{Q} O O H$

- $R_{6}: H O O \dot{Q} O O H \longrightarrow H P K E T+O H$

- $R_{7}: H P K E T \longrightarrow$ Products $+O H$

where $R H$ is the initial alkane; $R$. is an alkyl radical; $R O O$. is an alkylperoxy radical; $\cdot Q O O H$ is a hydroperoxy-alkyl radical; $H O O Q O O H$ is a dihydroperoxyalkyl radical; $\cdot O O Q O O H$ is a peroxy-hydroperoxy-alkyl radical; and $H P K E T$ is a hydroperoxy-ketone.

The ignition event is due to the rapid formation of $\mathrm{OH}$ radical by successive decompositon of $H O O Q O O H$ and $H P K E T$, and is essentially characterized by a single step of heat release [43]. This is consistent will the results obtained by Boettcher et 
al. [2] in their study of the effect of heating rate on the low temperature combustion of hexane-air mixtures.

At higher temperature $(600-800 \mathrm{~K})$, the increased competition between $\mathrm{R}_{4}$ and

- $R_{8}: \cdot Q O O H \longrightarrow$ alkene $+\mathrm{HO}_{2}$

- $R_{9}: \cdot Q O O H \longrightarrow$ cyclicether $+\mathrm{OH}$

- $R_{10}: Q O O H \longrightarrow \beta-$ scissionproducts

induces an increase of the ignition delay-time (negative temperature coefficient region or NTC region) and the appearance of a two-stage ignition event [40, 41].

In the present study, the species profiles were monitored at $T \leq 500 \mathrm{~K}$ and ignition was never observed. It is thus important to understand that the two-stage oxidation process that we are reporting is not similar to the two-stage ignition process which is taking place in the NTC region. Some similarities as well as some differences between the chemistry observed in the "non-explosive" and the "explosive" regimes can be underlined.

For the experiments performed at a temperature close to $500 \mathrm{~K}$ and characterized by two phases of oxidation of very different rates, the detection of a strong absorption feature peaking at $260 \mathrm{~nm}$ seems to indicate that the oxidation pathways responsible for the formation of hydroperoxy-ketones $\left(R_{1}\right.$ to $\left.R_{6}\right)$ dominate. This conclusion is supported by (i) the value of the activation energy of the first step of oxidation (see Figure $7 \mathrm{~b}$ )); and (ii) the insensitivity to pressure of this first step of oxidation when it is observed (see Figure $6 \mathrm{~b}$ )). Considering the chemical sequence $R_{1}$ to $R_{6}$, the limiting step is $R_{3}$, the isomerization of the alkylperoxy radical $R O O$. into the hydroperoxy-alkyl radical $\cdot Q O O H$. The activation energy of $R_{3}$ is typically around $110 \mathrm{~kJ} / \mathrm{mol}$ [41] which is consistent with the activation energy we found for the first step of oxidation, $\approx 100 \mathrm{~kJ} / \mathrm{mol}$. In addition, since $R_{3}$ is a first-order reaction, it does not depend on pressure which explain the insensitivity to pressure [41]. It is noted that in the "explosive" regime, the rapid decomposition of the hydroperoxy-ketones leads to the rapid formation of smaller carbonyls, such as ketones and aldehydes, and 
of $\mathrm{OH}$ radicals [44]. However, the UV spectra that we obtained do not demonstrate absorption features characteristics of these decomposition species. Under these conditions, the hydroperoxy-ketone may be stable enough so that no detectable amounts of smaller carbonyls and $\mathrm{OH}$ radical are formed.

For the experiments performed at a temperature below 460-470 K and characterized by a single phase of oxidation, no hydroperoxy-ketones were detected and consequently, it may be concluded that the sequence $R_{1}$ to $R_{6}$ is not a dominant pathway in this range of temperature. Unfortunately, the data collected during these experiments are not sufficient to clearly identify the dominant chemical pathways at these lower temperatures.

It is noted that physical effects such as heat losses and radical destruction at the wall may have significant impact on the results we presently obtained. We have shown, see Boettcher et al. [2] and Melguizo-Gavilanes et al. [45], that close to the ignition temperature, heat losses may dominates chemical heat release which results in a non-explosive event during which fuel consumption and subsequent chemical reactions are taking place. The impact of radical destruction at the wall is difficult to assess and a detailed evaluation of this effect is beyond the scope of the present study.

\subsection{Flammability tests}

\subsubsection{Flammability at low temperature}

In order to test the flammability of mixtures subjected to a thermal treatment in the vicinity of the auto-ignition temperature, the approach of Boettcher et al. [2] was adopted. Following the thermal treatment, the temperature was increased at a rate of up to $8 \mathrm{~K} / \mathrm{min}$. Under these conditions, Boettcher et al. observed ignition of the mixture with significant pressure rise.

Figure 8 and Figure 9 show representative examples of experimental results obtained for a thermal treatment with a pressure in the range $120-130 \mathrm{kPa}$ and a temperature of $465 \mathrm{~K}$ and $495 \mathrm{~K}$, respectively. At $465 \mathrm{~K}$, a continuous and slow decrease of the normalized fuel ( $\mathrm{C}-\mathrm{H}$ bond) concentration is observed during the ther- 
mal treatment performed at constant temperature. As the temperature is ramped up at $8 \mathrm{~K} / \mathrm{s}$, a more rapid decrease of fuel concentration takes place over several hundred seconds and without fast pressure transient. At $495 \mathrm{~K}$, a rapid decrease of fuel concentration is observed during the initial part of the thermal treatment performed at constant temperature. As the temperature is ramped up at $6 \mathrm{~K} / \mathrm{s}$, no significant change of the signal intensity is taking place until the very end of the experiment where the absorption by $\mathrm{C}-\mathrm{H}$ bonds starts increasing. This increase is likely due to the absorption of some decomposition products of the hydroperoxy-ketones formed during the thermal treatment. As in the case of the thermal treatment made at 465 $\mathrm{K}$, no fast pressure transient is seen for the thermal treatment made at $495 \mathrm{~K}$. These results seem to indicate that most of the species which contribute to the absorption at the He-Ne laser wavelength are formed within about $500 \mathrm{~s}$ and are relatively stable at temperature up to $530 \mathrm{~K}$. In any case, it seems the thermal treatment successfully inerted the mixtures.
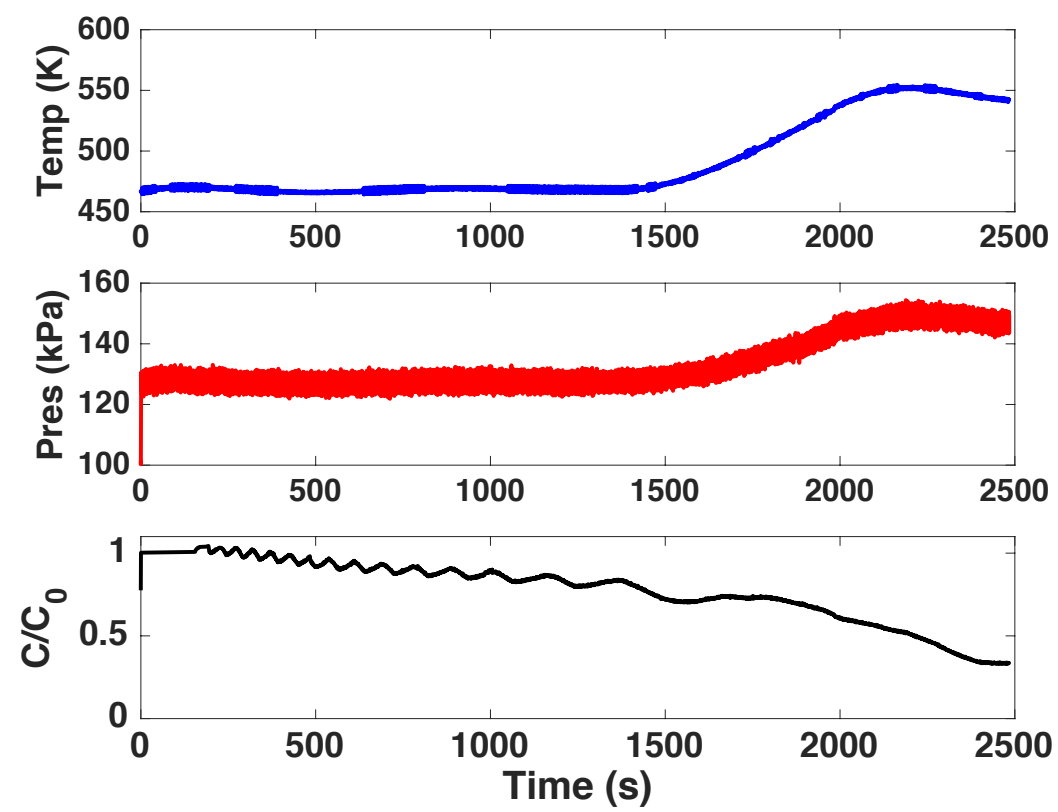

Figure 8: Evolution of the temperature, pressure and He-Ne laser normalized intensity during the thermal treatment at $465 \mathrm{~K}$ followed by heating at $8 \mathrm{~K} / \mathrm{min}$ of a rich $n$-hexane-air mixture. Conditions: $\Phi=1.1, \mathrm{P}=127 \mathrm{kPa}$. 

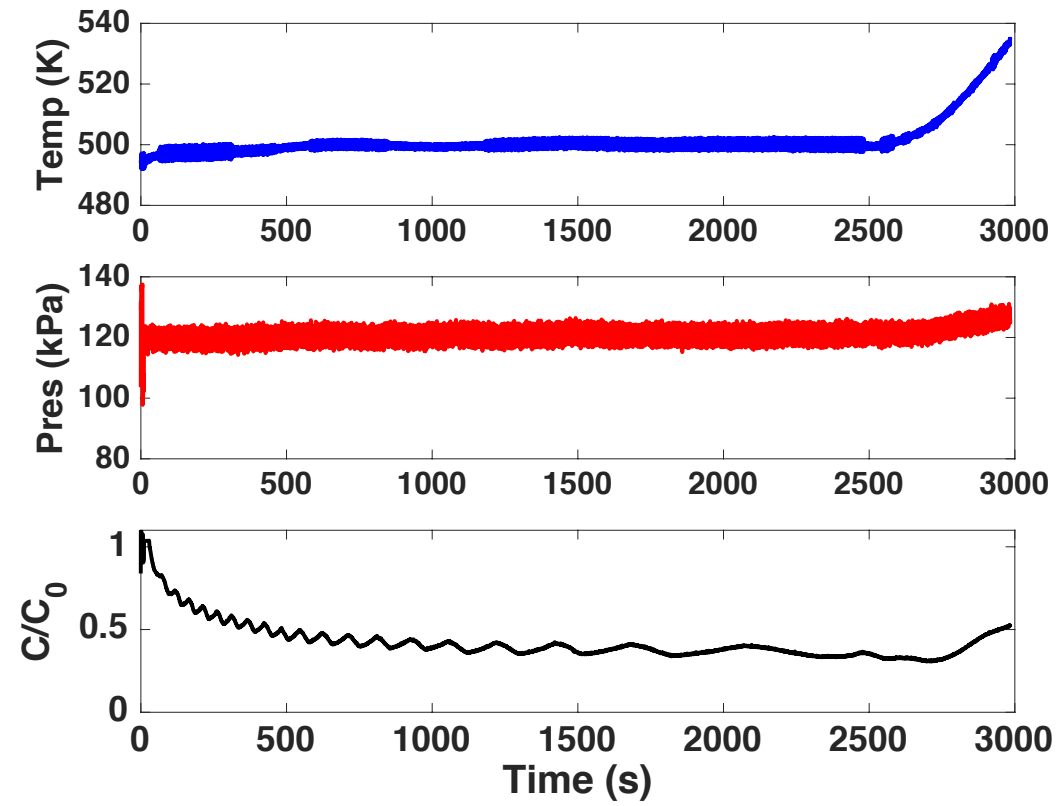

Figure 9: Evolution of the temperature, pressure and He-Ne laser normalized intensity during the thermal treatment at $495 \mathrm{~K}$ followed by heating at $6 \mathrm{~K} / \mathrm{min}$ of a rich $n$-hexane-air mixture. Conditions: $\Phi=1.1, \mathrm{P}=120 \mathrm{kPa}$.

\subsubsection{Flammability at high temperature}

To test the flammability of the mixtures at high temperature, following the thermal treatment, the high-temperature glow plug was turned on to check if the mixture had been inerted or not. For all conditions investigated, the glow plug, which had a surface temperature higher than $1300 \mathrm{~K}$, initiated ignition. The resulting combustion process was characterized using pressure and $\mathrm{OH}^{*}$ emission measurements.

Figure 10 a) presents the peak pressure rise observed for all the experiments. The peak pressure rise is insensitive to the residence time, but depends on the temperature: the higher the temperature, the smaller the peak pressure rise. There are three effects that contribute to the reduction in peak pressure: (i) heat losses to the vessel surrounding, (ii) partial reaction of the fuel, and (iii) for a given energy content $(Q)$, the pressure ratio during a constant volume combustion is given by $P_{2} / P_{1}=N_{2} / N_{1} \times\left(1+Q / C_{p} T_{1}\right)$, and thus a higher $T_{1}$ will lead to a lower pressure jump. This latter effect is accounted for in equilibrium calculations. To estimate the magnitude of the two former effects, the experimental results were compared 
with the theoretical adiabatic constant volume explosion pressure computed with the Equil code of the Chemkin II package [46].

The impact of heat losses was determined by performing experiments with a residence time of a few seconds and lower temperatures. In these cases, no hexane was consumed before ignition and a difference of approximately $35 \%$ was found between measured peak pressures and values computed from adiabatic, constant-volume complete combustion simulations. The effect of partial consumption of the fuel could then be evaluated by considering that, by the time of ignition, a fraction of hexane was converted to hydroperoxy-hexanone (from $5 \%$ at $420 \mathrm{~K}$ to $30 \%$ at $500 \mathrm{~K}$ ). As seen in Figure 10 b), the peak pressures estimated by this methodology are within $15 \%$ of the measured values. The conversion of hexane to hydroperoxy-hexanone accounts for a decrease of the peak pressure by approximately 10-15\%.

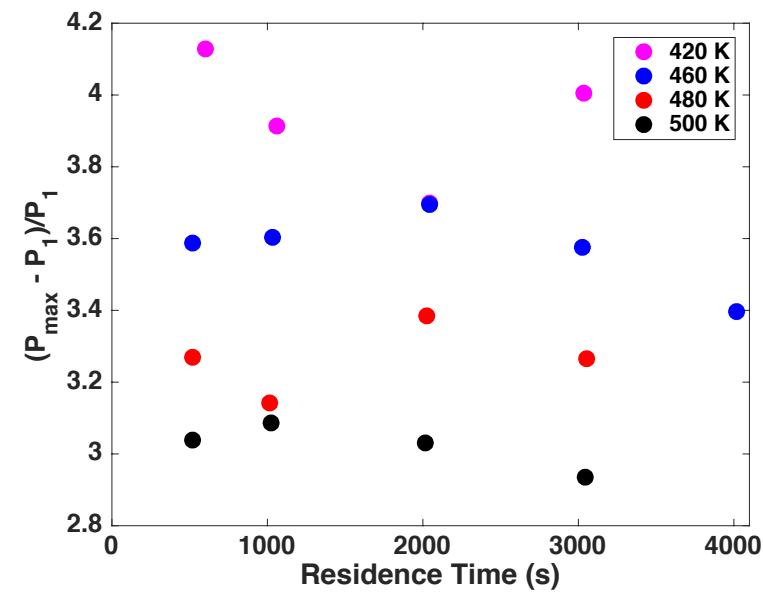

a) Peak pressure

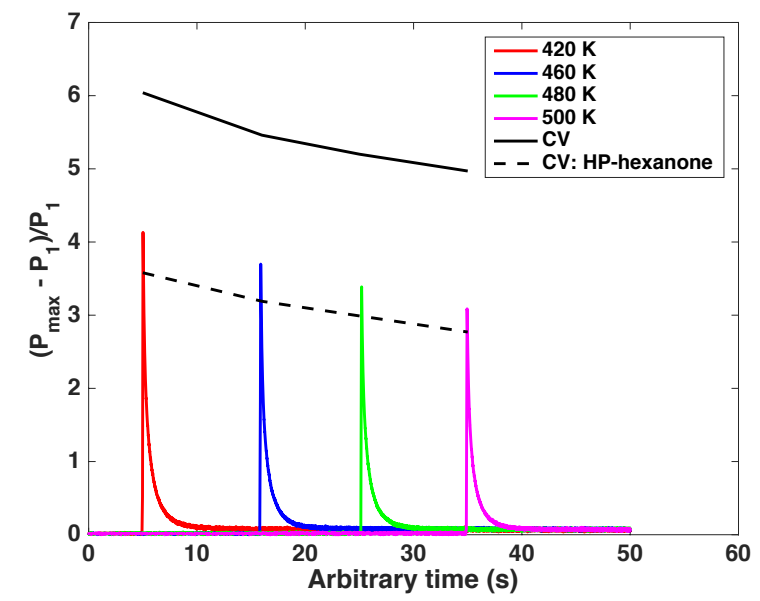

b) Pressure profiles

Figure 10: Explosion pressure peaks and profiles after ignition with a high-temperature glow plug of a partially oxidized $n$-hexane-air mixture. Conditions: $\Phi=1.1, \mathrm{~T}=420-500 \mathrm{~K}, \mathrm{P}=90-130 \mathrm{kPa}$, Residence time $=500-4000 \mathrm{~s}$. In b): solid line: adiabatic constant volume explosion without hexane consumption, dashed line: non-adiabatic (65\%) CV explosion calculation with partial conversion of hexane (from $5 \%$ at $420 \mathrm{~K}$ to $30 \%$ at $500 \mathrm{~K}$ ) into hydroperoxy-hexanone.

The $\mathrm{OH}^{*}$ emission following the ignition by the glow plug was measured for each experiment. Figure 11 a) shows typical emission profiles obtained at different temperatures for a residence time of 3000 seconds. The voltage applied to the PMT was 


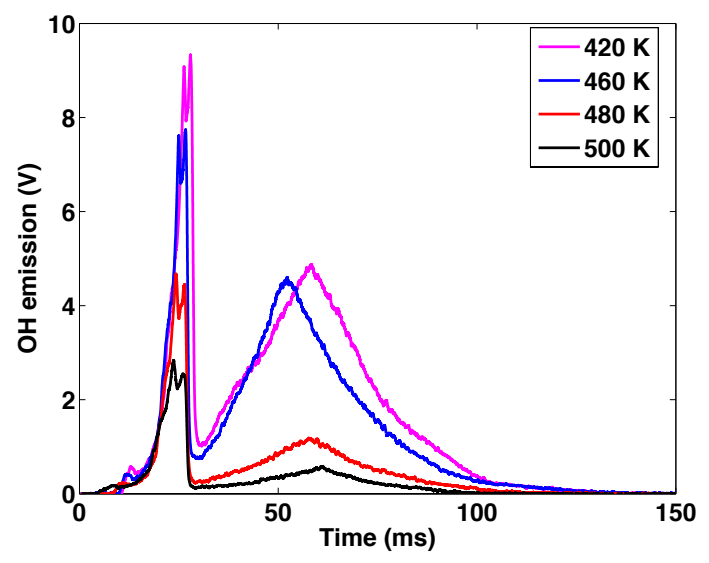

a) $\mathrm{OH}^{*}$ emission profiles

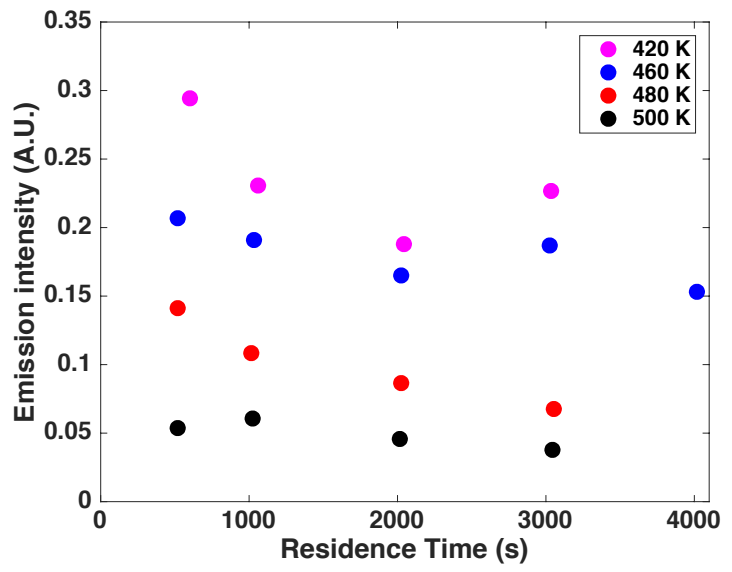

b) Integrated $\mathrm{OH}^{*}$ emission

Figure 11: $\mathrm{OH}^{*}$ emission profiles and integrated intensities after ignition with a high-temperature glow plug of a partially oxidized $n$-hexane-air mixture. Conditions: $\Phi=1.1, \mathrm{~T}=420-500 \mathrm{~K}, \mathrm{P}=90$ $130 \mathrm{kPa}$, Residence time $=500-4000 \mathrm{~s}$.

maintained constant for all experiments to allow for a comparison of the emission intensity depending on the temperature and residence time. The area below the curve has been extracted and will be referred to as the emission intensity. Results are shown in Figure 11 b). The emission intensity decreases strongly with temperature (at $500 \mathrm{~K}$ it is almost 5 times lower than at $420 \mathrm{~K}$ ) and is insensitive to residence time. As the temperature is increased, more hexane is consumed and transformed to partially oxidized intermediate and combustion products. The intensity of the emission by $\mathrm{OH}^{*}$ radicals depends on the amount of combustible species in the mixture. Transformation of hexane into combustion products, $\mathrm{H}_{2} \mathrm{O}$ and $\mathrm{CO}_{2}$, induces a decrease of the amount of species that can lead to the production of $\mathrm{OH}^{*}$. Although still flammable, partially oxidized compounds such as carbonyls, would likely produce less $\mathrm{OH}^{*}$ as compared to alkanes. As previously observed in our laboratory, reflected shock heated acrolein-oxygen-argon mixtures [47] as well as acetaldehydeoxygen-argon mixtures [48] produced much less intense $\mathrm{OH}^{*}$ emission signals than small hydrocarbon-nitrous oxide(-oxygen) mixtures under similar thermodynamic conditions and dilution levels [49]. 


\section{Conclusion}

Motivated by the concept of developing a new inerting system for aircraft based on a long thermal process in the vicinity of the auto-ignition temperature, the oxidation of $n$-hexane-air mixtures has been studied using various spectroscopic diagnostics and temperature and pressure measurements. The results show that, depending on the temperature, the reaction is characterized by a one-phase or a two-phase process.

At temperatures below 450-470 $\mathrm{K}$, the reaction proceeds at a constant rate and leads to the production of $\mathrm{CO}_{2}$ and $\mathrm{H}_{2} \mathrm{O}$. At temperatures above $470 \mathrm{~K}$, the reaction proceeds in two phases: the first phase is fast and induces a rapid consumption of $\mathrm{C}-\mathrm{H}$ bonds and oxygen, and the formation of $\mathrm{H}_{2} \mathrm{O}, \mathrm{CO}_{2}$, and $\mathrm{C}=\mathrm{O}$ and $\mathrm{C}-\mathrm{O}$ bonds (mostly from hydroperoxy-ketones), whereas the second phase is slower and is characterized by a continuous production of $\mathrm{H}_{2} \mathrm{O}$ and $\mathrm{CO}_{2}$ and consumption of hydroperoxy-ketones. Because the kinetics during the first phase is about ten times faster than during the second phase, the extent of the oxidation process depends weakly on the residence time when it is longer than $1000 \mathrm{~s}$.

The flammability of the mixtures following the thermal process was checked using both a low- and a high-temperature ignition source. While inerting seems to have been achieved for a low-temperature ignition source (heated vessel), the hightemperature ignition source (glow plug) led to an explosion in all conditions studied. Flammable components were thus still present inside the vessel at the end of the thermal treatment. Unless significant amount of carbon dioxide and water are formed in the course of the thermal process, there will always be certain conditions under which the mixture will ignite, because partially oxidized, flammable products such as carbonyls are formed. Our results indicate that the specific thermal treatments we considered are not adequate to make the atmosphere completely inert. This does not preclude the feasibility of thermal treatment as a component of an inerting system but additional processing of the mixture or modification of the thermal treatment regime will be needed to insure that remaining mixture is inert. 


\section{Acknowledgments}

The present work was mostly carried out in the Explosion Dynamics Laboratory of the California Institute of Technology. The authors are grateful to the Boeing Company for funding this research through a Strategic Research and Development Relationship Agreement CT-BA-GTA-1. RM was also supported by the 1000 Young Talent of China program and a start-up fund of the Center for Combustion Energy of Tsinghua University. 


\section{References}

[1] S. Bane, Spark ignition: experimental and numerical investigation with application to aviation safety, Ph.D. thesis, California Institute of Technology (2010).

[2] P. A. Boettcher, R. Mével, V. Thomas, J. E. Shepherd, The effect of heating rates on low temperature hexane air combustion, Fuel 96 (2012) 392-403.

[3] P. Boettcher, Thermal ignition, Ph.D. thesis, California Institute of Technology (2012).

[4] P. Boettcher, S. Menon, B. Ventura, G. Blanquart, J. Shepherd, Cyclic flame propagation in premixed combustion, Journal of Fluid Mechanics 735 (2013) $176-202$.

[5] NTSB, In-flight breakup over the atlantic ocean trans world airlines flight 800 boeing 747-131, n93119 near east moriches, new york july 17, 1996, Tech. Rep. NTSB/AAR-00/03, National Transportation Safety Board (2000).

URL https://www.ntsb.gov/investigations/AccidentReports/Reports/ AAR0003.pdf

[6] S. Bane, J. Shepherd, E. Kwon, A. Day, Statistical analysis of electrostatic spark ignition of lean h2/o2/ar mixtures, International Journal of Hydrogen Energy 36 (3) (2011) $2344-2350$.

[7] S. Bane, J. Ziegler, P. Boettcher, S. Coronel, J. Shepherd, Experimental investigation of spark ignition energy in kerosene, hexane, and hydrogen, Journal of Loss Prevention in the Process Industries 26 (2) (2013) 290 - 294.

[8] S. Bane, J. Ziegler, J. Shepherd, Investigation of the effect of electrode geometry on spark ignition, Combustion and Flame 162 (2) (2015) 462 - 469.

[9] S. Coronel, R. Mével, S. P. M. Bane, J. E. Shepherd, Experimental study of minimum ignition energy of lean $\mathrm{h}_{2}-\mathrm{n}_{2} \mathrm{O}$ mixtures, Proceedings of The Combustion Institute 34 (1) (2013) 895-902. 
[10] S. Coronel, Thermal ignition using moving hot particles, Ph.D. thesis, California Institute of Technology (2016).

[11] S. Coronel, J. Melguizo-Gavilanes, R. Mevel, J. Shepherd, Experimental and numerical study on moving hot particle ignition, Combustion and Flame 192 (2018) 495-506.

[12] R. Mével, U. Niedzielska, J. Melguizo-Gavilanes, S. Coronel, J. Shepherd, Chemical kinetics of n-hexane-air atmospheres in the boundary layer of a moving hot sphere, Combustion Science and Technology 188 (11-12) (2016) 22672283 .

[13] FAA, Reduction of fuel tank flammability in transport category airplanes, Tech. Rep. Federal Register, Vol. 73, No. 140, FAA (2008).

URL https: //www.gpo.gov/fdsys/pkg/FR-2008-07-21/pdf/E8-16084.pdf

[14] Y. Okafor, E.G.and Sun, Z. Lu, Safety assessment of an on board inert gas generating system, Recent Patents on Engineering 6 (2012) 70-79.

[15] Y. Cai, X. Bu, G. Lin, B. Sun, Y. Zeng, Z. Li, Experimental study of an aircraft fuel tank inerting system, Chinese Journal of Aeronautics 28 (2) (2015) 394 402.

[16] FAA, Recommendations of the arac fuel tank inerting harmonization working group, Tech. Rep. FAA-22997-6, FAA (2002).

URL https://www.faa.gov/regulations_policies/rulemaking/ committees/documents/media/ECftiwgT1-7142000.pdf

[17] M. Burns, W. Cavage, R. Morrison, S. S., Evaluation of fuel tank flammability and the faa inerting system on the nasa 747 sca, Tech. Rep. DOT/FAA/Ar04/41, FAA (2004).

URL https://www.fire.tc.faa.gov/pdf/04-41.pdf

[18] P. Dagaut, M. Reuillon, M. Cathonnet, Experimental study of the oxidation of n-heptane in a jet stirred reactor from low to high temperature and pressures up to 40 atm, Combustion and Flame 101 (1995) 132-140. 
[19] K. Zhang, C. Banyon, C. Togbé, P. Dagaut, J. Bugler, H. Curran, An experimental and kinetic modeling study of n-hexane oxidation, Combustion and Flame 162 (11) (2015) $4194-4207$.

[20] R. Mével, P. A. Boettcher, J. E. Shepherd, Absorption cross section at $3.39 \mu \mathrm{m}$ of alkanes, aromatics and substituted hydrocarbons, Chemical Physics Letters $531(2012)$ 22-27.

[21] A. Farooq, J. Jeffries, R. Hanson, Measurements of $\mathrm{co}_{2}$ concentration and temperature at high pressures using if -normalized wavelength modulation spectroscopy with second harmonic detection near $2.7 \mu \mathrm{m}$, Applied Optics 48 (2009) $6740-6753$.

[22] H. Li, G. Rieker, X. Liu, J. Jeffries, R. Hanson, Extension of wavelengthmodulation spectroscopy to large modulation depth for diode laser absorption measurements in high-pressure gases, Applied Optics 45 (5) (2006) 1052-1061.

[23] H. Keller-Rudek, G. K. Moortgat, R. Sander, R. Sörensen, The mpi-mainz uv/vis spectral atlas of gaseous molecules of atmospheric interest, Earth System Science Data 5 (2) (2013) 365-373.

[24] P. Limao-Vieira, S. Eden, N. Mason, S. Hoffmann, Electronic state spectroscopy of acetaldehyde, ch3cho, by high-resolution $\{$ VUV $\}$ photo-absorption, Chemical Physics Letters 376 (5-6) (2003) 737-747.

[25] R. Martinez, A. Buitrago, N. Howell, C. Hearn, J. Joens, The near u.v. absorption spectra of several aliphatic aldehydes and ketones at $300 \mathrm{k}$, Atmospheric Environment. Part A. General Topics 26 (5) (1992) 785 - 792.

[26] Y. Chen, L. Zhu, J. Francisco, Wavelength-dependent photolysis of nbutyraldehyde and i-butyraldehyde in the 280-330-nm region, The Journal of Physical Chemistry A 106 (34) (2002) 7755-7763.

[27] Y. Tang, L. Zhu, Wavelength-dependent photolysis of n-hexanal and n-heptanal in the 280-330-nm region, The Journal of Physical Chemistry A 108 (40) (2004) 8307-8316. 
[28] E. Jiménez, B. Lanza, E. Martínez, J. Albaladejo, Daytime tropospheric loss of hexanal and trans-2-hexenal: Oh kinetics and uv photolysis, Atmospheric Chemistry and Physics 7 (6) (2007) 1565-1574.

[29] C. Cantrell, J. Davidson, A. McDaniel, R. Shetter, J. Calvert, Temperaturedependent formaldehyde cross sections in the near-ultraviolet spectral region, The Journal of Physical Chemistry 94 (10) (1990) 3902-3908.

[30] J. D. Rogers, Ultraviolet absorption cross sections and atmospheric photodissociation rate constants of formaldehyde, The Journal of Physical Chemistry 94 (10) (1990) 4011-4015.

[31] M. Yujing, A. Mellouki, The near-uv absorption cross sections for several ketones, Journal of Photochemistry and Photobiology A: Chemistry 134 (1) (2000) $31-36$.

[32] F. Jorand, L. Kerhoas, A. Heiss, J. Einhorn, K. Sahetchian, Determination of the ultra violet absorption cross section of hexyl-ketohydroperoxides in solution in acetonitrile, Journal of Photochemistry and Photobiology A: Chemistry 134 (1) (2000) 119-125.

[33] D. Jaynes, B. Beam, Hydrocarbon gas absorption by a hene laser beam at a 3.39- $\mu$ wavelength, Applied Optics 8 (8) (1969) 1741-1742.

[34] D. Olson, W. Mallard, W. Gardiner, High temperature absorption of the 3.39 he-ne laser line by small hydrocarbons, Applied Spectroscopy 32 (5) (1978) 489-493.

[35] T. Tsuboi, K. Inomata, Y. Tsunoda, A. Isobe, K.-I. Nagaya, Light absorption by hydrocarbon molecules at $3.392 \mu \mathrm{m}$ of he-ne laser, Japanese Journal of Applied Physics 24 (1985) 8-13.

[36] J. Drallmeier, Hydrocarbon absorption coefficients at the 3.39- $\mu \mathrm{m}$ he-ne laser transition, Applied Optics 42 (6) (2003) 979-982. 
[37] A. Klingbeil, J. B. Jeffries, R. Hanson, Temperature- and pressure-dependent absorption cross sections of gaseous hydrocarbons at $3.39 \mu \mathrm{m}$, Measurement Science and Technology 17 (2006) 1950-1957.

[38] M. Alrefae, E.-T. Es-sebbar, A. Farooq, Absorption cross-section measurements of methane, ethane, ethylene and methanol at high temperatures, Journal of Molecular Spectroscopy 303 (0) (2014) 8 - 14.

[39] M. Campbell, K. Freeman, D. Davidson, R. Hanson, \{FTIR\} measurements of mid-ir absorption spectra of gaseous fatty acid methyl esters at $\mathrm{t}=25-500^{\circ} \mathrm{c}$, Journal of Quantitative Spectroscopy and Radiative Transfer 145 (0) (2014) 57 $-73$.

[40] F. Battin-Leclerc, Detailed chemical kinetic models for the low-temperature combustion of hydrocarbons with application to gasoline and diesel fuel surrogates, Progress in Energy and Combustion Science 34 (4) (2008) 440-498.

[41] P. Zhao, C. Law, The role of global and detailed kinetics in the first-stage ignition delay in NTC-affected phenomena, Combustion and Flame 160 (11) (2013) 2352-2358.

[42] H. J. Curran, Developing detailed chemical kinetic mechanisms for fuel combustion, Proceedings of the Combustion Institute (2018), https://doi.org/10.1016/j.proci.2018.06.054.

[43] P. Zhao, W. Liang, S. Deng, C. Law, Initiation and propagation of laminar premixed cool flames, Fuel 166 (2016) 477 - 487.

[44] R. Mével, K. Chatelain, P. A. Boettcher, J. E. Shepherd, Low temperature oxidation of n-hexane in a flow reactor, Fuel 126 (2014) 282-293.

[45] J. Melguizo-Gavilanes, P. A. Boettcher, A. Gagliardi, V. L. Thomas, R. Mével, Two-dimensional numerical simulation of the transition between slow reaction and ignition, Proceedings of the Joint US Sections Meeting of the Combustion Institute 9 (2015). 
[46] R. Kee, J. Grcar, M. Smooke, J. Miller, A fortran program for modelling steady laminar one-dimensional premixed flames, Tech. Rep. SAND85-8240, Sandia International Laboratories (1993).

[47] K. Chatelain, R. Mével, S. Menon, G. Blanquart, J. Shepherd, Ignition and chemical kinetics of acrolein-oxygen-argon mixtures behind reflected shock waves, Fuel 135 (2014) 498-508.

[48] R. Mével, K. Chatelain, G. Blanquart, J. Shepherd, An updated reaction model for the high-temperature pyrolysis and oxidation of acetaldehyde, Fuel 217 (2018) 226-239.

[49] R. Mével, J. E. Shepherd, Ignition delay-time behind reflected shock waves of small hydrocarbons-nitrous oxide(-oxygen) mixtures, Shock Waves 25 (2015) $217-229$. 